\title{
Numerical Analysis on the Stability Behavior of a Dynamical System on the Deposit and Loan of a Bank
}

\author{
Novriana Sumarti*, H. Fansuri \\ Industrial and Financial Mathematics Research Group, Bandung Institute of Technology, Jalan Ganesha 10, Bandung 40132, Indonesia
}

Received: 11 October 2014 / Accepted: 30 November 2014

Abstract:
A dynamical system is one of sophisticated techniques using mathematical equation ste changes in the state of the
times based on the current state. It will also show small changstem.
depending on the model. This is called stability analysis of a dynamical system
equation and develop a dynamical system of the form:
\[ \mathrm{dD} / \mathrm{dt}=\mathrm{f}\left(\mathrm{t}, \mathrm{D}, \mathrm{L}, \mathrm{r}_{-} \mathrm{D}, \mathrm{r}_{-} \mathrm{L}\right) \]
$\mathrm{dD} / \mathrm{dt}=\mathrm{f}\left(\mathrm{t}, \mathrm{D}, \mathrm{L}, \mathrm{r}_{-} \mathrm{D}, \mathrm{r}_{-} \mathrm{L}\right)$

Here $\mathrm{D}$ and $\mathrm{r}_{-} \mathrm{D}$ are the volume of deposit and its rate, $\mathrm{L}$ and $\mathrm{r}_{-} \mathrm{L}$ are the volume of loan and its rate, and $\mathrm{r}$ is the interbank market rate. One system of determining the interest rate is a floating system that is to follow the state of the market. At a particular period of time, we analyze the stability behavior of the solutions numerically when the rates of loan and deposit follow sinus and cosines functions in various combinations. It concludes that the stability behavior of their equilibrium will be similar when the rates of deposit and interbank market are the similar functions. This reflects the state of a downward-sloping demand for loans with respect to the loan rate and an upward-sloping demand for deposits with respect to the deposit rate.

Key words: Model of bank, Monti-Klein equation, numerical method, ordinary differential equations, stability analysis

\section{Introduction}

The need of reliable techniques to model the behavior of commercial banks in a country in a period of time is inevitable nowadays. The model could benefit in the decisions for the appropriate regulation of banking industries be applied. Recently the derivation of dynamical models for macroeconomics is more in quantitative approach rather than modeling approach such as using dynamical systems. Some papers examining stochastic different equations for interest rate models are including $[1,2,3]$. In $[4,5,6]$, the LotkaVolterra system was used to formulate respectively the dynamics of market share, the dynamic among Mother Bank, Subsidiary Bank, and Individuals suppliers/clients, and a dynamic of Deposit and Loan volumes. In [7], a dynamical model on bank profit was built to analyze the Return-on-Assets (RoA) and Return-on-Equity (RoE) of a bank. In [8], the economic aspects of the stochastic dynamics model of bank assets and liabilities were discussed. In [9], the question of the interdependence between decisions about loans and deposits in the banking regulation is answered using the Monti-Klein model. In [10], the authors explained the scopes of economies between loan and deposit in an oligopolistic market based on the same model.
A new model proposed in this research in order to achieve a convenient form of the model to show the interdependence of loan and deposit via a system of dynamical model. The model is to forecast the volumes of loan and deposit of commercial banks in a general period of time. A dynamical model consists of a set of differential equations that can determine the observed states, for example bank's loan and deposit volumes, for all future times based on the current state. It can be shown in its phase portrait where the behavior of the solution's trajectories and velocities are depicted in all conditions. It will also could show small changes in the state of the system create either small or big changes in the future depending on the model. In its stability analysis on a dynamical system, the equilibrium points whereabouts the velocity of the solutions are zero, are discovered in order to understand the behavior of their nearby solutions. For instance, if they are going in spiral or star-like trajectories approaching these points, then it is the stable condition. Or they are passing by or going out of these points, and then it is the unstable condition. These behaviors can be interpreted into the conditions of the bank in general.

\footnotetext{
*Corresponding author: Novriana Sumarti,

E-mail: novriana@math.itb.ac.id
} 
The dynamical model constructed in this paper can be implemented for calculating the reserve requirement regulated by the Central Bank, who is responsible for achieving and maintaining monetary stability. The reserve requirement needs the information of the volumes of loan and deposit for time to time. This regulation is made to control rate of inflation and conditions of excess liquidity in banks. However, the requirement imposes a cost on the private sector equal to the amount of forgone interest on these reserves [13]. It is said that the higher the level of reserve requirements, the greater the costs imposed on the private sector. At the same time, however, higher reserve requirements may smooth the implementation of monetary policy and damp volatility in the reserves market. In [14], the introduction of the reserves gives impact on the existence and efficiency properties of Nash equilibria of the model of double Bertrand competition. In [15], the estimation of optimal reserve holdings for countries under various monetary regimes was proposed. In [16], the significance of interest rates on the optimal international reserve holdings was discussed.

In the next section, we proposed a mathematical model based on the Monti-Klein model on the bank's profit. The numerical solution of the derived system of differential equations will be discussed in Section 3. Finally the numerical analysis of the dynamical system will be explained in Section 4.

\section{Mathematical Model of Banking}

Having improved Monti-Klein model [17, 18], a bank's profit function can be expressed by the optimization problem below:

$$
\begin{aligned}
\max \pi & =r_{L} L+r M+r_{B} B+r_{R_{2}} R_{2} \\
& -r_{D} D-C(D, L)
\end{aligned}
$$

such that $L+M+R_{1}+R_{2}+B=D+K$ where $D$ and $L$ are volumes of deposit and loan. $M, R_{1}, R_{2}$ and $B$ are respectively volumes of net position of the bank on the interbank market, the primary and secondary reserves, the amount of equity held by the bank and government Treasury bills. $r_{D}, r_{L}, r, r_{R_{2}}$ and $r_{B}$, are respectively the related interest rates of $D, L, M, R_{2}$ and $\mathrm{B}$. Note that we assume there is no interest rate for $R_{1}$ and $K . C(D, L)$ is a cost function that describes the bank's management costs of servicing deposit D and loan L.

Based on [19], the reserve requirement, or GWM (Giro Wajib Minimum) in the Indonesian language, are classified into primary $R_{1}$, secondary $R_{2}$ and LDR (Loan to Deposit Ratio). $R_{1}$ and $R_{2}$ are proportion of the volume of the deposits, or $R_{1}=\kappa_{1} D$ and $R_{2}=\kappa_{2} D$. Stated in the previous paragraph, only the secondary GWM could bear interest with rate $r_{R_{2}} . B$ and $K$ are proportions of the volumes of the deposit and loan respectively, or $B=\delta D$ and $K=\gamma L$. The net position of the bank on interbank market is defined as $M=\left(1-\kappa_{1}\right.$ $\left.\kappa_{2}-\delta\right) D+(1-\gamma) L$.

For simplicity, some assumptions are applied as following:

- No stochastic change on rate of return of deposit and the bond.

- No risk of default on loan.

- No liquidity problem occurs.

- No various types of loan and deposit, so they are unique.

- The cost function has been simplified.

The monopoly bank which represents the banking industry as a whole, have a downward-sloping demand for loans with respect to the loan rate and an upwardsloping demand for deposits with respect to the deposit rate. Later, those two conditions will be a validation later whether the model is acceptable or not.

A dynamical system of $\mathrm{D}$ and $\mathrm{L}$ is obtained by implementing chain rule in derivation on these volumes with respect to time on Equation (1). Having in the first stage of the mathematical modeling, we define the loan and deposit's interest rates using the simplification assumption that these quantities are varying periodically as in functions of cosine and sine. In the further stages, we can define those functions which are more related to the real world, so more complicated analysis will be needed. The constructed dynamical system of D and $\mathrm{L}$ will be as following.

$$
\begin{gathered}
\frac{d D}{d t}=b \frac{d r_{D}}{d t}+ \\
+\frac{\left(-\frac{d r_{D}}{d t}+\left(1-\kappa_{1}-\kappa_{2}-\delta\right)\right) D+\left(-\frac{d r_{L}}{d t}+(\gamma-1)\right) L}{r\left(1-\kappa_{1}-\kappa_{2}-\delta\right)+r_{B} \delta-r_{R_{2}} \kappa_{2}-r_{D} \frac{\partial C}{\partial D}} \\
\frac{d L}{d t}=g \frac{d r_{L}}{d t}+ \\
\frac{\left(-\frac{d r_{D}}{d t}+\left(1-\kappa_{1}-\kappa_{2}-\delta\right)\right) D+\left(-\frac{d r_{L}}{d t}+(\gamma-1)\right) L}{r_{L}+r \gamma-\frac{\partial C}{\partial L}}
\end{gathered}
$$

We assume that $\frac{\partial C}{\partial D}=\frac{\partial C}{\partial L}=c D+c L$, so $C(D, L)=$ $k D L+\frac{1}{2} k D^{2}+\frac{1}{2} k L^{2}$ where $c$ and $k$ are constants.

We also assume $\frac{\partial D}{\partial r_{D}}=b, 0<b<1$ and $\frac{\partial L}{\partial r_{L}}=g,-1<$ $g<0$, which can be interpreted as the public's respond to the alteration of the interest rates of loan and deposit. The values of $r_{D}, r_{L}$ and $r$, which are given as the approximate situation in Indonesia, range respectively from 0.02 to $0.06,0.08$ to 0.14 , and 0.06 to 0.07 . To model the fluctuation of these values, we assume that

$$
\begin{gathered}
r_{D}=0.04+0.01 \sin 2 \pi t, \\
r_{L}=0.11+0.03 \cos 2 \pi t, \\
r=0.06+0.01 \sin 2 \pi t .
\end{gathered}
$$

Here $t=1$ equals about 20 years in real time. 
Having substituting some values of parameters and initial conditions, the numerical solution for the dynamical system can be obtained. In the next section we will discuss the analysis of the behavior of the solutions numerically on this system.

\section{Numerical Solutions}

In this section we simulate the dynamical system in the previous chapter. We consider the initial values of the system by choosing $\mathrm{D}(0)=100$ and various values of the ratio between $\mathrm{L}(0)$ and $\mathrm{D}(0)$, or $\operatorname{LDR}(0)=\frac{L(0)}{D(0)}$. Their values are less than or equal to 1.5 (from 0.2 to 1.5 ) and greater than 2 . Solutions to the system with those initial values are named alphabetically from A to $\mathrm{F}(\mathrm{LDR}(0)$ is from 0.2 to 1.5$)$ and from $\mathrm{G}$ to $\mathrm{L}(\operatorname{LDR}(0)$ is greater than 2). Figures $1 \mathrm{a}$ and $1 \mathrm{~b}$ show plots of deposit to time. In figure 1 (left), the larger ratio of $\operatorname{LDR}(0)$ the lower its position's plot. As the contrary, in figure 1 (right) the larger ratio of $\operatorname{LDR}(0)$, the higher its position. We could use larger values of $\operatorname{LDR}(0)$ but it seems they occurs rarely in the reality. Figure 2 shows plot of loan to time where the larger ratio of $\operatorname{LDR}(0)$ the higher its position.

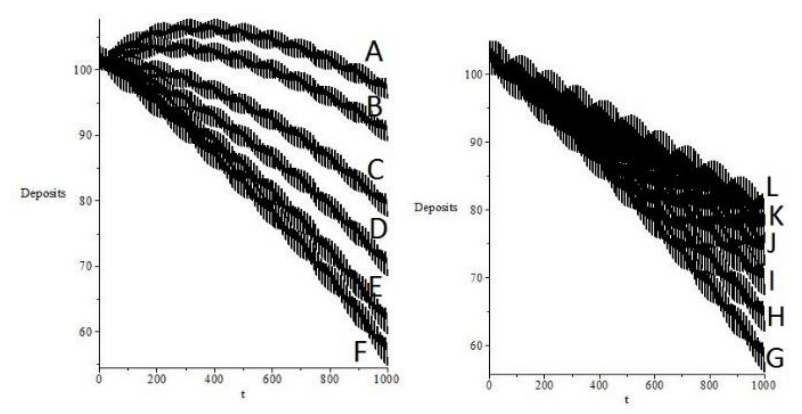

Figure 1. Plots of deposit to time.

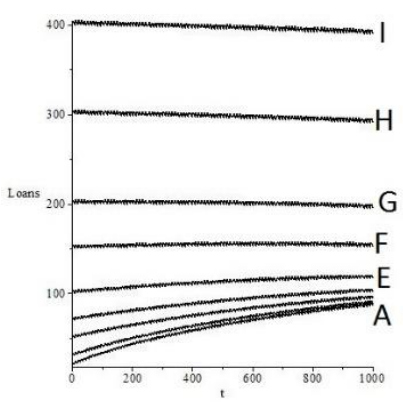

Figure 2. Plots of loan to time.

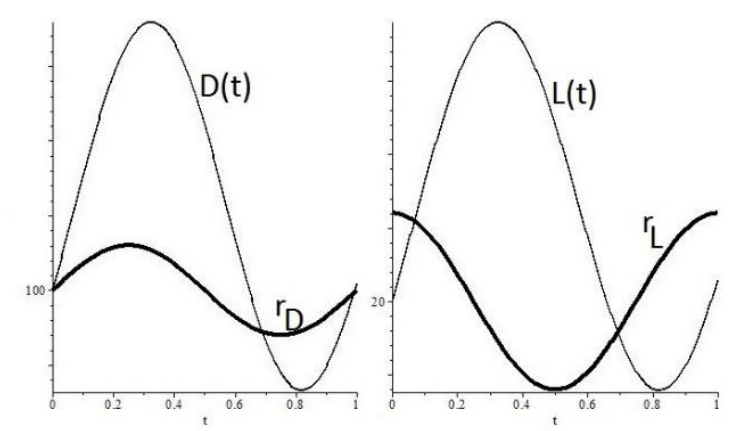

Figure 3. Deposit and loan with their rates.
Figure 3 show the behavior of solutions $\mathrm{D}(\mathrm{t})$ and $\mathrm{L}(\mathrm{t})$ with respect to their rates respectively. In the left plot, the graph of deposit increase and decrease consistently with the deposit interest rate. This contradict behavior is shown the right plot, where the increase of the loan graph follows the decrease of the loan interest rate. Notice that the scale of the plots are adjusted for clear visibility.

In the next section, the stability of the system will be analyzed numerically in particular values of time.

\section{Numerical Stability Analysis}

The dynamical system discussed in Section 1 is nonautonomous where the variable time is directly stated in the system. For simplicity, the stability analysis near to the equilibrium points in this research is conducted numerically where we observe the equilibrium points for particular values of $t$ in a given periods. The stability analysis is being observed for $0 \leqslant \mathrm{t} \leqslant 1$. For other intervals of time, the results will be similar.

For a specific value of $t$, the Jacobian matrix of the system is evaluated at its equilibrium point. We observe the eigenvalues of the matrix. Figure 4 shows the graphs of equilibrium points of $\mathrm{D}$ and $\mathrm{L}$ with respect to time, and their types of stability/instability. For $0 \leqslant t<0.02$ and $0.91 \leqslant \mathrm{t} \leqslant 1$, it is type 3 or saddle where the eigenvalues are in different sign. For $0.02 \leqslant \mathrm{t}<0.26,0.38 \leqslant \mathrm{t}<0.45$, and $0.76 \leqslant \mathrm{t}<0.81$, it is type 1 or stable sink, where both eigenvalues are negative. For $0.26 \leqslant \mathrm{t}<0.38,0.52 \leqslant$ $\mathrm{t}<0.76$ and $0.81 \leqslant \mathrm{t}<0.91$, it is type 2 or unstable source where both eigenvalues are positive.

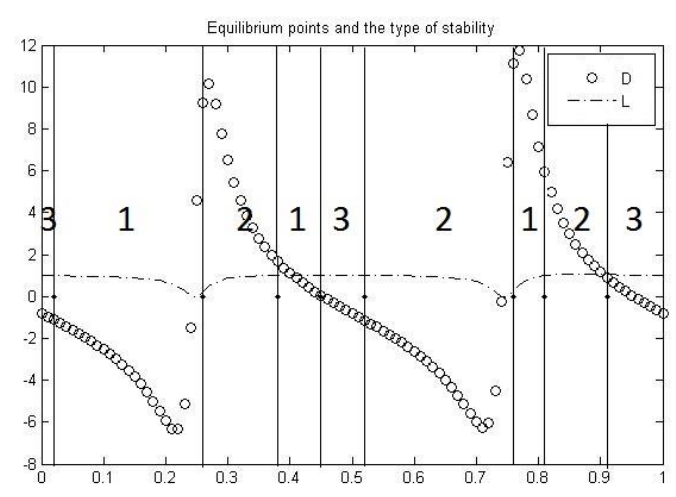

Figure 4. Equilibrium points for given values of time and their types of stability/instability.

\section{Discussion and Conclusions}

In Section 1 we build a dynamical system in order to see the changes of volumes of deposit and loan of a bank with respect to time. Their graphs shows desired behavior when they are compared with the graphs of their related interest rates. It shows that people are encouraged to save their money in the bank when the 
interest rate of deposit is high. In the contrary, people are discouraged to take loan when the interest rate of loan is so high. The other condition follows consistently. We can conclude that the dynamical system is validated in this point of view.

The choice of initial values of $\operatorname{LDR}(0)$ gives different behavior of the solutions. The situation when volumes of $\mathrm{D}$ will larger if the initial ratio of LDR is lower occurs only for values of the initial ratio between 0.2 and 1.5 . These values are common in the reality. The situation is flipped when the initial ratio is greater than 1.5. The first situation will not occur for greater initial value $\mathrm{D}(0)$. We will need further study to find the specific limit of $\mathrm{D}(0)$ when the first situation disappears. It seems the magnitude of the initial volume $\mathrm{D}$ with the same value of LDR could give different behavior of the solutions.

The desired condition of stability is stable sink when $0.02 \leq t<0.26,0.38 \leq t<0.45$ and $0.76 \leq t<0.81$, because it relates to the stability of the bank. However, it change quickly when time changes. We need further study on the situation when the condition of volume deposit and loan is stable so hopefully we could implement a control in the system in order to maintain the stability.

\section{Acknowledgement}

This research is sponsored by ITB Research and Innovation Program, Jan-Dec 2014, No. PN-648.

\section{References}

[1] L. Giet and M. Lubrano, A minimum Hellinger distance estimator for stichastic differential equations: An application to statistical inference for continuous time interest rate models, Comp. Stat., \& Data Analysis, 52, 2008, $2945-2965$.

[2] J. Zhao, Long time behaviour of stochastic interest rate models, Insurance : Maths and Econs., 44, 2009, 459463.

[3] H.Y. Wong and J. Zhao, An artificial boundary method for the Hull-White model of American interest rate derivatives, App. Math. and Comp., 217, 2011, 4627 4643.

[4] A.W. Wijeratne, F. Yi, J. Wei, Bifurcation analysis in the diffusive Lotka-Volterra system: An application to market economy, Chaos, Solitons and Fractals, 2007.

[5] C.A. Comes, Banking system: Three level LotkaVolterra model, Procedia Economic and Finance, 3, $2012,251-255$.

[6] N. Sumarti, R. Nurfitriyana, and W. Nurwenda, A Dinamical System of Deposit and Loan Volumes based on the Lotka-Volterra Model, AIP Conference Proceedings, 1587, 2014, 92; doi: 10.1063/1.4866541.

[7] M.A. Petersen and I. Schoeman, Modeling of Banking Profit via Return-on-Assets and Return-on-Equity, Proc. of the WCE, 2, 2008, London, U.K.

[8] J. Mukuddem-Petersen, M.A. Petersen, I.M. Schoeman and B.A. Tau, Dynamic modelling of bank profits, Applied Financial Economics Letters, 4, 2008, 157-161.

[9] P. Dvorak, Rethinking the Monti-Klein model of banking industry: new insights about the separability of loans and deposits decisions, Discussion Paper no. 2005-138, CERGE-EI

[10] S. Yamazaki and H. Miyamoto, A note on bank behaviour and monetary policies in an oligopolistic market, Industrial Organization 0408003, EconWPA, 2004.

[11] E. Boyce and R.C. DiPrima, Elementary Differential Equation and Boundary Value Problems, John Wiley \& Sons, 7 ed., 2001,

[12] P. Glendinning, Stability, instability and chaos: an introduction to the theory of nonlinear differential equations, Cambridge UP, 1994.

[13] Board of Governors of the Federal Reserve System, Reserve Requirements: History, Current Practice, and Potential Reform, Federal Reserve Bulletin June 1993, 569-589.

[14] L.A. Toolsema, Reserve requirements and double Bertrand competition among banks, Applied Economics Letters, 8, 2001, 291- 293.

[15] P. Flood and N. Marion 2002, \{Holding international reserves in an era of high capability mobility\}, IMF Working Paper, International Monetary Fund WP/02/62.

[16] C.P. Balla and J. Reyes, International reserve holdings: interest rates matter, Applied Economics Letters, 16, 2009, 343-348.

[17] K. Matthews and J. Thompson, The economics of Banking, John Wileys and Sons Ltd, 2005.

[18] X. Freixas and J.C. Rochet, Microeconomics of Banking, 2nd ed., the MIT Press Cambridge, Massachusetts, 2008.

[19] Bank of Indonesia Regulation No 12/19/PBI/2010. 